\title{
The Overview of Oral Cancer and Risk Factors in Bangladesh
}

\author{
Nargish Sultana, ${ }^{1, *}$ Muttalib Malik ${ }^{2}$ \\ ${ }^{1}$ University of Tasmania, Hobart, Australia \\ ${ }^{2}$ Bangabandhu Sheik Mujib Medical University, Dhaka, Bangladesh \\ *Corresponding author: nargish.sultana@utas.edu.au
}

Received August 31, 2014; Revised September 15, 2014; Accepted September 18, 2014

\begin{abstract}
Oral health is very important part of human health and cannot lead good life without it. Poor oral health often factors of oral cancer. Oral cancer is very dreadful disease that affects many people each year all over the world and it is eleventh most dominate cancer in the world. Oral cancer is also reported in Bangladesh and more than 7000 people are diagnosed each year and $6.6 \%$ people are died. This paper shows the total oral cancer picture in Bangladesh based on different literatures and cancer registry from the web and also different risk factors that associated with this disease.
\end{abstract}

Keywords: oral health, oral cancer, WHO, Bangladesh

Cite This Article: Nargish Sultana, and Muttalib Malik, "The Overview of Oral Cancer and Risk Factors in Bangladesh.” International Journal of Dental Sciences and Research, vol. 2, no. 5A (2014): 8-10. doi: 10.12691/ijdsr-2-5A-3.

\section{Introduction}

Oral health is very important part of human health and cannot lead healthy life without it. A good oral health enables a person to eat, speak and socialize without active diseases, discomfort or embarrassment. Many general diseases are first indication of poor oral health and one of them is oral cancer. Oral cancer is very disastrous disease that affects many people each year all over the world and it is the eleventh most dominant cancer in the world according to the World Health Organization (WHO) [9]. Oral cancer mostly affects in the area of lips, tongue, mouth, salivary glands and oropharynx ([1-9]).

In Bangladesh more than 7000 people are newly diagnosed each year and among them $6.6 \%$ people are died $([1,2,3,4,5])$ due to their life style and other factors. However, Government has already taken lots of initiative to make people conscious such as advertisement, community hospital for rural area ([2,3]). But, there is no good infrastructure about oral health in Bangladesh. Due to this challenge, many incidences are not captured in the cancer registry. Also, there no dedicated website about the cancer or not many publications are found on the web. In this paper, we capture the statistics of oral cancer based on available cancer registry in Bangladesh and also discuss different risk factors. This paper helps oral practitioners about oral cancer scenario in Bangladesh. The paper is organized in the following way: Section 2 describes about the material and methods, Section 3 illustrates about oral cancer scenario in Bangladesh and finally we describe about the conclusion.

\section{Materials and Method}

The National Institute of Cancer Research and Hospital (NICRH), Dhaka is a sub-specialized hospital for cancer patient care and education of professionals [5]. This only a public hospital in Bangladesh where people usually come to seek treatment about cancers. It is equipped with trained manpower and other logistics as a part of the Government's commitment to develop this hospital in to a centre of excellence. It is a centre hub for keeping the archive information about the cancer patients. The NICRH started a cancer registry in 2005 for the first time in Bangladesh with technical assistant from the World Health Organization. Current report cover three years 2005 to 2007 which was published in 2009 [5].

In order to build these registry the following approach were used.

- All patients had to buy a prescription ticket and had their details registered in a register.

- Patients were then sent to the duty nurse for informations such as patient identification, demographics, tobacco use...

- If the patient were already diagnosed, details of diagnosis including method of diagnosis, the clinical stage of the disease and the broad type of treatment instituted are obtained. All precautions were maintained to avoid multiple counts of same patient.

- After completing the session each patient was directed to the respective departments for further examination.

Apart from NIRCH in Bangladesh, other private organizations also handle cancer patients. They usually 
sent this information to NIRCH. The cancer registry report were referred different incidences that were diagnosed in Bangladesh population in particular timeframe. The definition of oral cancer used in this study included World Health Organisation International Classification of Diseases Oncology third edition codes C00-C14. These sites of oral cancer include lip (excluding skin of lip), tongue, gum, floor of mouth, palate, and other parts of the mouth, parotid glands and other major salivary glands $([2,5,7,8,9])$ and furthermore, literatures were review from the website ([8-17]) and extract the information about Bangladesh.

\section{Oral Cancer in Bangladesh}

Bangladesh is one of the under developing and over populated country in south Asia. The below table shows population according the age group.

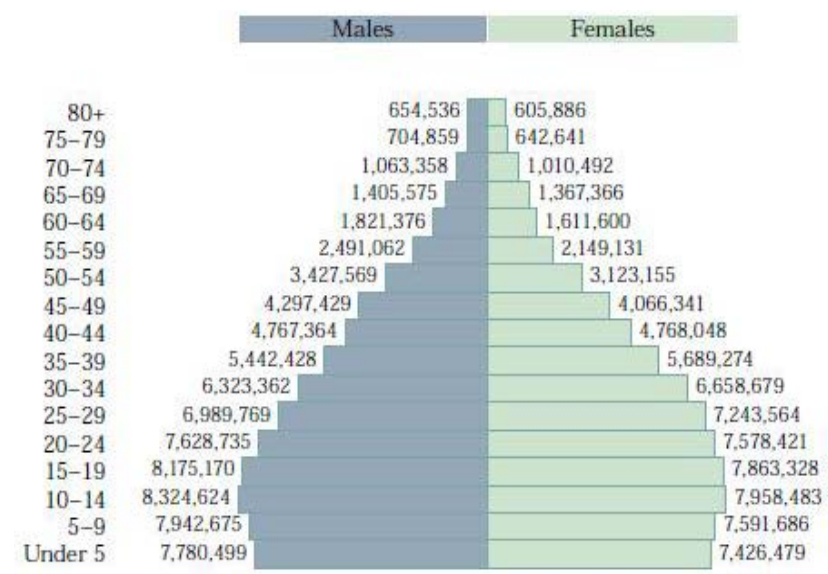

Figure 1. Population of Bangladesh by sex and age group [17]

There are 13, 00000 cancer patients in Bangladesh, with about 200,000 patients newly diagnosed with cancer each year. Among these all cancer patients, 7120 were affected in lip, oral cavity and pharynx. Considering other Asian countries the number of patient were not higher ([1-17]). However, the percentage of incidence and mortality rate are increasing every year.

\subsection{Incidence}

Total patients were 2058 diagnosed for oral cancer due to various causes([3,4,5]).

\subsection{Trends}

The ratio of oral cancer are increasing among rural people in Bangladesh. In 2005, 608 were reported; in 2006, 695 were reported; in 2007, 755 were reported regarding oral cancer. So the trends of oral cancer are reportedly increasing in Bangladesh, particularly under privileged area. Current report says that 11.9 percent people are affected by oral cancer [5].

\subsection{Age and Gender and Sites}

The cancer registry reported that the 25 percent were males and similar number were reported for female. The age groups were 15-24, 25-34, 35-44, 45-54, 55-64, 65-74 and 74-75 years. However, oral cancer were mostly notified among 45-54 ages' people. The affected sites were lip, base of the tongue, lingual tonsil, gum, floor of the mouth, hard palate, soft palate, uvula, palate, buccal mucosa, vestibule of mouth, oral cavity parotid gland, submandibular gland, tonsil fossa, tonsil, vallecular, anterior surface of epiglottis, bronchial cleft, oropharynx. Among all sites, tongue, oral cavity, and parotid gland were highest affected sites $([2,3,4,5])$.

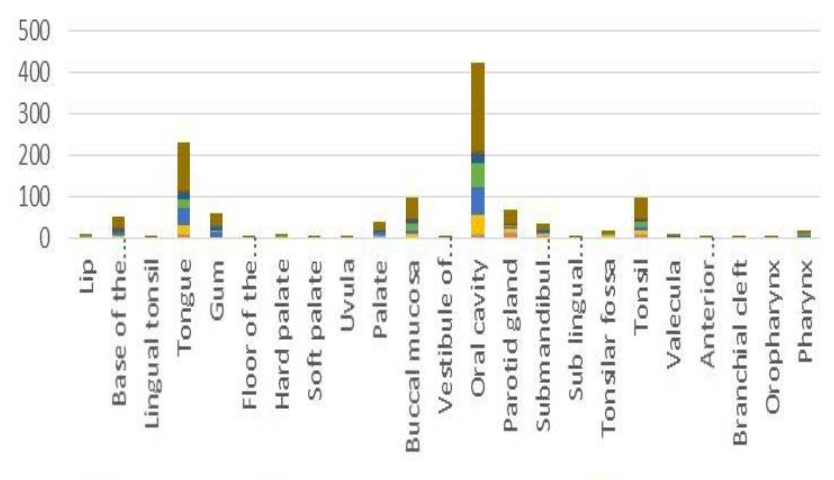

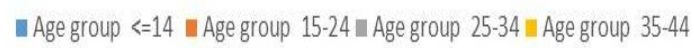
—Age group 45-54 $\backsim$ Age group 55-64 $\backsim$ Age group 65-74 $\backsim$ Age group 75-84

- Age group $<=85$ - Age group Total

Figure 2. Oral cancer by age and sites [5]

\subsection{Mortality}

The mortality rate of males were $8.3 \%$ and females were $4.3 \%$ for oral cancer. According the International Agency for Research on Cancer is noted that $6.6 \%$ of people are affected in oral cancer comparing other cancers.

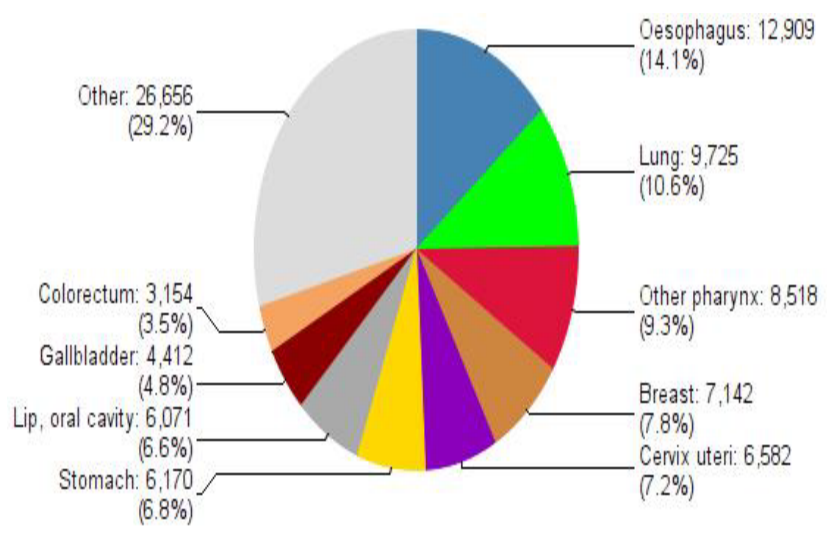

Figure 3. Mortality rate for cancers in Bangladesh [2]

Though Government has taken lots of initiative in order to control the oral cancer but rural people still not alert about their oral health problems as well as they are not interested to visit the dentist.

\subsection{Risk Factors}

- Tobacco

More than $90 \%$ of oral cancer cases report using tobacco products in Asian countries. It is used in smoking as well as smokeless forms. Betel quid chewing is the most common form of tobacco chewing in Bangladesh and also reported in Asia-Pacific regions. Betel quid consists of areca nut, betel leaf, catechu, zarda and slaked lime. 
About $10 \%$ of the world's population chew betel quid regularly. Smoking includes use of cigarettes, bidi, and hookah. Though cigarette smoking is seen in all Asian countries, bidi smoking is common in countries like India, Pakistan, Sri Lanka and Bangladesh. Bidi is prepared by rolling dried tobacco flakes into a dried Temburni leaf and secured with thread. Smoking bidi is an important risk factor contributing to a considerable number of oral cancer cases in India, Bangladesh, Nepal, Pakistan and Sri Lanka. Bidi smokers are 4 times at risk of developing oral cancer compared to non-smokers ([3,8,11,13,14,15,16]).

\section{- Alcohol Consumption}

Drinking alcohol is an important risk factor for oral cancer in Bangladesh. In China, India, Pakistan, Sri Lanka, Bangladesh, Nepal and Thailand spirits are consumed more commonly [8].

\section{- Food habit}

There are no well-designed epidemiological studies from Asian countries regarding food habit. A few studies have been able to present some relation with oral cancer. Increasing risk was seen with high consumption of combination (meat/by products dairy, fermented/salted food) and traditional food (starch and beverages) whereas a protective effective was observed with a prudent diet (fruits and vegetable) after adjusting for habits $([8,10,15])$.

- Viral Infection

Virus also major actor in the aetiology of oral cancers. Many virus have been identified in this aspect including Epstein Bar Virus (EBV), Human Simplex virus-1(HSV-1) and Human papilloma virus (HPV) types 16 and 18. Current evidence suggests that HPV 16 is associated with tonsil cancer, base of tongue cancer and other oropharyngeal cancer sites ([8-17]).

\section{- Oral Hygiene}

Poor oral hygiene has been addressed as risk factor for oral cancer. In one study reported that $85 \%$ of oral patients has poor oral hygiene. Poor oral hygiene related risk factor is around $60 \%$ for men and $35 \%$ were women [14].

\section{- Family history of malignancy}

Family heritage of malignancies could be risk factor. Currently a study identified that family history is probable factor for oral cancer. This field need to be more exploration $([8,9,10,11])$.

\section{Conclusion}

The main challenge for maintaining of oral cancer is the lower social-economic of the majority of the population in Bangladesh. Apart from this, lack of infrastructure and health workers, illiteracy, lack of awareness among general population about the side effects of tobacco, and prevalent cultural beliefs lead to delays is seeking treatment. The community hospital in rural area in Bangladesh can play a vital role to inform people about the good oral health. In future, family history based oral cancer research will be conducted.

\section{Acknowledgement}

Authors would like to thanks World Health Organization, National Institute of Cancer Research and Hospital, Dhaka Bangladesh, Bangabandhu Sheik Mujib Medical University, Bangladesh and University of Tasmania, Australia.

\section{References}

[1] Ferlay, J., Shin, H. R., Bray, F., Forman, D., Mathers, C., \& Parkin, D. M. (2010). Estimates of worldwide burden of cancer in 2008: GLOBOCAN 2008. International journal of cancer, 127(12), 2893-2917.

[2] Globocan 2012: Estimated Cancer Incidence, Mortality and Prevalence Worldwide in 2012. Available from http://globocan.iarc.fr/Default.aspx [Accessed on 31 August, 2014].

[3] Ahmed, F., \& Islam, K. M. (1990). Site predilection of oral cancer and its correlation with chewing and smoking habit--a study of 103 cases. Bangladesh Medical Research Council Bulletin, 16(1), 17-25.

[4] Uddin AK, Khan ZJ, Islam J, Mahmud AM. Cancer care scenario in Bangladesh. South Asian J Cancer 2013;2: 102-4.

[5] Cancer Registry Report National Institute of Cancer Research and Hospital 2005-2007. Available from: http://whobangladesh.

healthrepository.org/bitstream/123456789/282/1/Publication_Canc er_Registry_Report.pdf [Accessed on 31 August 2014].

[6] Joshi, P., Dutta, S., Chaturvedi, P., \& Nair, S. (2014). Head and Neck Cancers in Developing Countries. Rambam Maimonides medical journal, 5(2).

[7] Warnakulasuriya, S. (2009). Global epidemiology of oral and oropharyngeal cancer. Oral oncology, 45(4), 309-316.

[8] Rao, S. V. K., Mejia, G., Roberts-Thomson, K., \& Logan, R. (2013). Epidemiology of oral cancer in Asia in the past decade-an update (2000-2012). Asian Pacific Journal of Cancer Prevention, 14(10), 5567-5577.

[9] World Health Organisation (WHO) Global data on incidence of oral cancer. WHO/NMH/CHP/HPR/ORH 2005.

[10] Spallholz, J. E., Mallory Boylan, L., \& Rhaman, M. M. (2004). Environmental hypothesis: is poor dietary selenium intake an underlying factor for arsenicosis and cancer in Bangladesh and West Bengal, India?. Science of the total environment, 323(1), 2132.

[11] Radoï, L., Paget-Bailly, S., Cyr, D., Papadopoulos, A., Guida, F., Schmaus, A., \& Luce, D. (2013). Tobacco smoking, alcohol drinking and risk of oral cavity cancer by subsite: results of a French population-based case-control study, the ICARE study. European Journal of Cancer Prevention, 22(3), 268-276.

[12] Sankaranarayanan, R. (1990). Oral cancer in India: an epidemiologic and clinical review. Oral surgery, oral medicine, oral pathology, 69(3), 325-330.

[13] Rahman, M., Sakamoto, J., \& Fukui, T. (2005). Calculation of population attributable risk for bidi smoking and oral cancer in south Asia. Preventive medicine, 40(5), 510-514.

[14] Petti, S. (2009). Lifestyle risk factors for oral cancer. Oral oncology, 45(4), 340-350.

[15] Merchant, A., Husain, S. S., Hosain, M., Fikree, F. F., Pitiphat, W., Siddiqui, A. R., ... \& Saeed, S. A. (2000). Paan without tobacco: an independent risk factor for oral cancer. International journal of cancer, 86(1), 128-131.

[16] Johnson, N. (2001). Tobacco use and oral cancer: a global perspective. Journal of Dental Education, 65(4), 328-339.

[17] Human Papillomavirus and Related Diseases report. Available at Reporthttp://www.hpvcentre.net/statistics/reports/BGD_FS.pdf [Accessed on 31 August, 2014]. 